\title{
Resonant CLL Non-Inverting Buck-Boost Converter
}

\author{
Masoud Jabbari ${ }^{\dagger}$, Saead Sharifi ${ }^{*}$, and Ghazanfar Shahgholian ${ }^{*}$ \\ $\dot{\dagger}^{*}$ Department of Electrical Engineering, Najafabad Branch, Islamic Azad University, Isfahan, Iran
}

\begin{abstract}
This paper presents a resonant non-inverting buck-boost converter in which all switches operate under ZCS conditions. In a symmetric configuration, a CLL resonant tank along with an inverter arm and a rectifying diode are employed. The diode is turned off at ZCS and hence the problem of its reverse recovery is obviated also. As a result switching losses and EMI are reduced and switching frequency can be increased. The converter can work at DCM and CCM depend on the switching frequency and the load-current. Experimental results from a $200 \mathrm{~W} / 200 \mathrm{KHz}$ laboratory prototype verify operation of the proposed converter and the presented theoretical analysis.
\end{abstract}

Key words: Non-inverting buck-boost, Resonant power conversions, Soft-switching, ZCS, Power supply.

\section{NOMENCLATURE}

$\mathrm{i}_{\mathrm{r}}, v_{\mathrm{r}} \quad$ resonant current/voltage.

$\mathrm{Z}_{\mathrm{r}} \quad$ characteristic impedance.

$\mathrm{R}, \mathrm{r} \quad \mathrm{load} /$ normalized resistance.

$\alpha \quad$ inductance ratio.

$\mathrm{L}_{\mathrm{r}} \quad$ resonant inductance.

$\mathrm{C}_{\mathrm{r}}, \mathrm{C} \quad$ resonant/output capacitor.

$\mathrm{f}_{\mathrm{r}}, \omega_{r} \quad$ resonant frequency.

A DC voltage gain.

$\mathrm{V}_{\mathrm{o}} \quad$ DC output voltage.

$\mathrm{V}_{\mathrm{s}} \quad$ DC input voltage.

ZCS zero-current switching.

ZVS zero-voltage switching.

ZCT zero-current transition.

ZVT zero-voltage transition.

EMI electromagnetic interference.

PBBC positive buck-boost converter.

RC resonant converter.

QRC quasi-resonant converter.

DCM discontinuous conduction mode.

CCM continuous conduction mode

\section{INTRODUCTION}

Buck-boost converter with non-inverting voltage gain is employed in many applications such as battery-backup

Manuscript received Jun. 18, 2012; revised Oct. 21, 2012

Recommended for publication by Associate Editor Sangshin Kwak.

${ }^{\dagger}$ Corresponding Author: jabbari.masoud@gmail.com

Tel: +98-331-229-1080, Najafabad Branch, Islamic Azad University

*Department of Electrical Engineering, Najafabad Branch, Islamic Azad University, Iran utilities, voltage stabilizers, fuel-cell systems, solar panels, portable apparatus, RF power amplifiers and PFC converters due to the ability of providing a wide range of voltage regulation [1]-[10]. The basic PWM non-inverting buck-boost converters are positive buck-boost converter (PBBC), SEPIC, and Zeta converter. In PBBC two switches and two diodes should be employed while SEPIC and Zeta converter possess two inductors and one coupling capacitor [1]-[11]. In [7], a new topology is proposed which includes one inductor and one coupled inductor plus two switches, two diodes and one extra capacitor which improves the instability of PBBC. However, despite of employing additional power elements all these converters are hard-switching.

To enhance power density and efficiency, and reduce electromagnetic interference (EMI) soft-switching techniques are successfully developed. Soft-switching conditions are attained by switching under zero-voltage (ZVS) and/or zero-current (ZCS) [11]-[26]. In Quasi-Resonant Converters (QRC), by adding a resonant network to the basic PWM

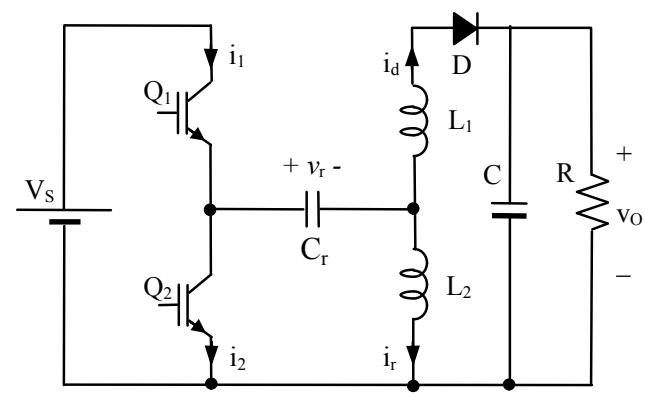

Fig. 1. Proposed non-inverting buck-boost converter. 
converter soft-switching conditions are provided [11]-[14]. This method is simple; however, there are disadvantages such as higher voltage/current stresses and loosing soft-switching conditions at transient-states. The family of ZVT/ZCT converters are derived by using a resonant network along with auxiliary switch(es) and diode(s). In these converters the resonances are under more control and thereby the converter behavior is improved, however the element number is increased [15]-[17].

Classically, a soft-switching non-inverting buck-boost converter can be derived by applying the auxiliary network of QRC or that of ZVT/ZCT converters to PBBC, SEPIC, and Zeta converter [11]-[17]. However, the result is a topology with many power elements. Since PBBC has two switches, providing soft-switching conditions for both switches needs more elements. E.g., in a ZCT PBBC, if by employing only one auxiliary cell soft-switching conditions can be provided for both main switches, the derived converter includes three switches and three diodes (to the best knowledge of authors such topology has not been reported yet). Or, SEPIC/Zeta QRC possesses at least three inductors. In QRCs, the converter main inductor(s) is taken large enough so that its current is assumed constant during one switching cycle [11]-[14]. Similarly, in ZVT/ZCT techniques the converter main inductor is still a bulky component since the PWM operation must be held. In Resonant Converters (RC), soft-switching conditions are attained by using a resonant network as the medium of power transfer. A major advantage is that in RCs no bulky inductor is required and hence the converter volume and size are reduced [18]-[26]. RCs with high-order resonant tank such as LLC, LCC, LCT, ... are developed to attain/improve the expected features [21]-[26]. However, almost all RCs are isolated topologies where even by omitting the transformer no common ground is found between input and output terminals.

A resonant non-inverting buck-boost converter is presented in this paper (Fig. 1). The proposed topology includes only two switches in a well-known bridge structure along with a CLL resonant tank in a symmetric configuration. Both switches commutate at soft-switching conditions as ZCS turn-on and ZCS/ZVZCS turn-off. As a result switching losses and EMI are considerably reduced and switching frequency can be increased. The rectifying diode at the output is turned off at ZCS and thereby the problem of reverse recovery of the FAST diode is properly obviated. Both inductors are resonant type and hence no bulky inductor is employed. Since two inductors are employed, another degree of freedom is provided in design procedure. Similar to Cuk, SEPIC, and Zeta converter, the capacitor $\mathrm{Cr}$ provides magnetic isolation between input and output terminals [11]. More significantly, $\mathrm{Cr}$ is also a part of the resonant network and possesses a small value. Experimental results from a $200 \mathrm{~W} / 200 \mathrm{KHz}$ laboratory prototype verify operation of the proposed converter and its presented theoretical analysis.

\section{PROPOSED CONVERTER ANALYSIS}

The converter can operate at three conditions: Discontinuous Conduction Mode (DCM), Continuous Conduction Mode (CCM), and deep-CCM. At deep-CCM, draining power from the input voltage source and supplying load are performed simultaneously which results in reducing current stresses and energy circulation. Similar to the most of RCs, the DC voltage gain is controlled by adjusting switching frequency. In a proper design, by decreasing the output current from full-load to no-load, the converter operating state moves from deep-CCM to DCM.

At full-load and at the minimum of the input voltage (the worst conditions), the converter is designed to operate at deep-CCM; or in other words, sets at its maximum power handling capability. By decreasing the load, or increasing the input voltage, the converter switching frequency is decreased to preserve the output voltage constant. Reduction in switching frequency leads to CCM operation. Further decrease of load or increase of input voltage results in DCM operation.

The converter operating conditions (DCM, CCM and deep-CCM) are defined considering the waveform of $\mathrm{L}_{2}$ current $\left(i_{r}\right)$. It is assumed that all elements are ideal and the output capacitor is large enough so that its voltage is constant during one switching cycle. The following quantities are defined:

$$
\begin{gathered}
\mathrm{L}_{\mathrm{r}}=\mathrm{L}_{1}+\mathrm{L}_{2} \\
\alpha=\frac{L_{2}}{L_{1}+L_{2}} \\
\omega_{r}=\frac{1}{\sqrt{L_{r} \times C_{r}}}, f_{r}=\frac{1}{T_{r}}=\frac{\omega_{r}}{2 \pi} \\
Z_{r}=\sqrt{L_{r} / C_{r}} \\
r=\frac{R}{Z_{r}} \\
A=V_{o} / V_{s}
\end{gathered}
$$

\section{A. DCM Operation}

Important waveforms and equivalent circuit of each operating mode are illustrated in Figs. 2(a) and 2(b).

Mode $I\left(t_{1}-t_{2}\right)$ : Prior to $t_{1}$, all semiconductor devices are OFF. At $t_{1}, Q_{1}$ is turned-on at ZCS $\left(i_{1}\left(t_{1}\right)=0\right)$ and the rectifying diode $\mathrm{D}$ starts conducting at $\mathrm{ZCS}\left(\mathrm{i}_{\mathrm{d}}\left(\mathrm{t}_{1}\right)=0\right)$. The capacitor $\mathrm{C}_{\mathrm{r}}$ charges through a resonance with $\mathrm{L}_{1}, \mathrm{~L}_{2}$. The input voltage source $V_{S}$ supplies the output via $L_{1}$ and increases the energy stored in the resonance tank via $\mathrm{L}_{2}$. At the end of this mode the diode current $i_{d}$ becomes zero. 


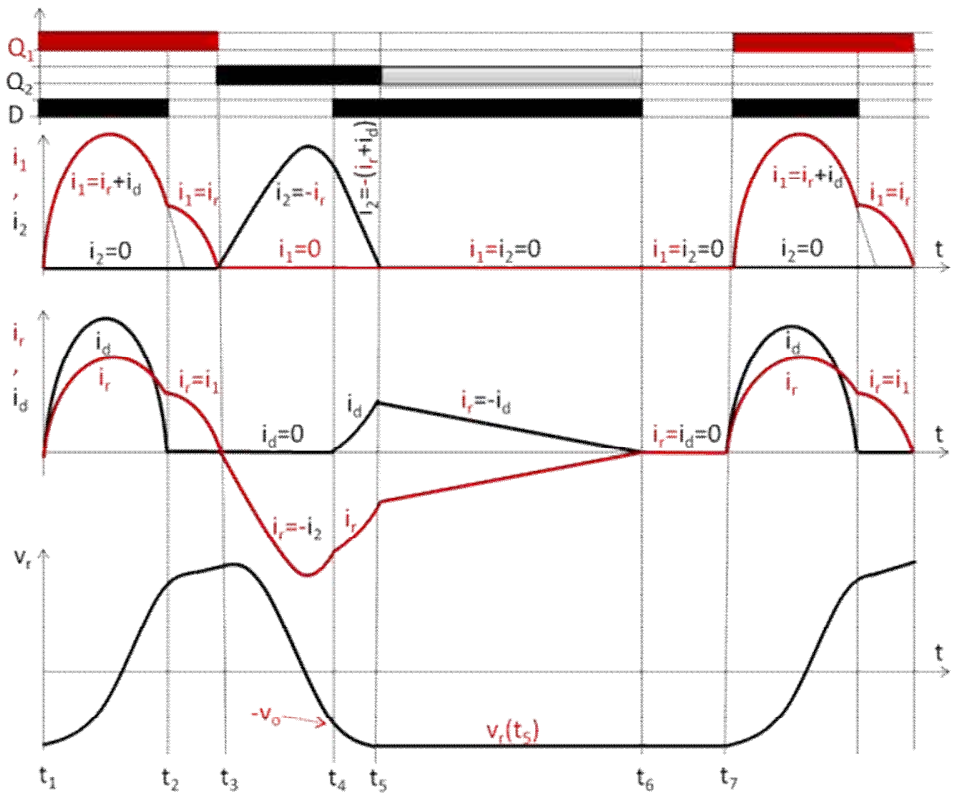

(a)
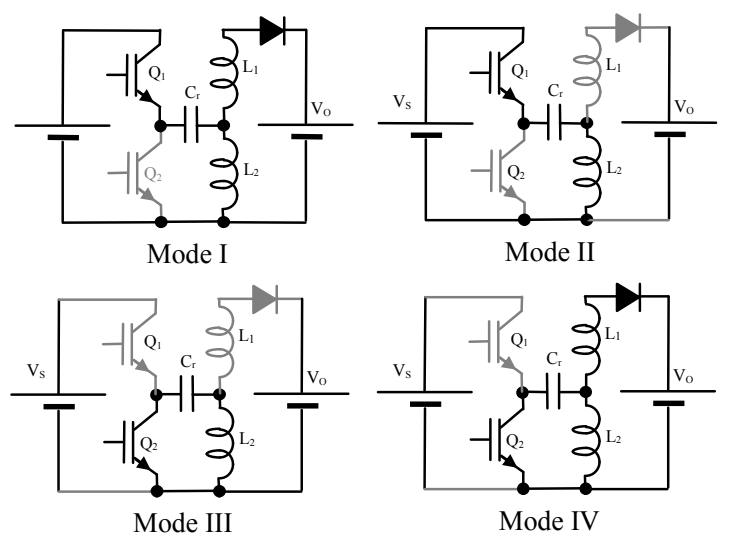

Mode III

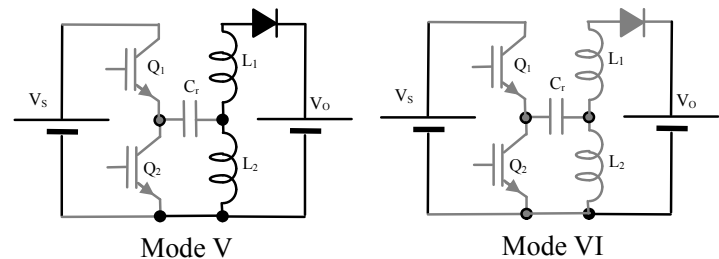

(b)

Fig. 2. (a) Waveforms of DCM operation, and (b) Operating modes.

$$
\begin{gathered}
v_{r}(t)=\left[v_{r}\left(t_{1}\right)-V_{s}+\alpha V_{o}\right] \cos \left(\omega_{r}\left(t-t_{1}\right)\right)+\left[V_{s}-\alpha V_{o}\right] \\
i_{r}(t)=-\frac{(1-\alpha)}{Z_{r}}\left[v_{r}\left(t_{1}\right)-V_{s}+\alpha V_{o}\right] \sin \left(\omega_{r}\left(t-t_{1}\right)\right) \\
+\frac{\omega_{r} \alpha(1-\alpha) V_{o}}{Z_{r}}\left(t-t_{1}\right)
\end{gathered}
$$

Mode II $\left(t_{2}-t_{3}\right)$ : At $\mathrm{t}_{2}$ the diode is turned off at ZCS but $\mathrm{Q}_{1}$ is still conducting until at $t_{3}$ the resonant current $i_{r}$ reaches zero. Then $\mathrm{Q}_{1}$ turns off at $\mathrm{t}_{3}$ under the ZCS conditions.

$$
\begin{gathered}
{\left[\begin{array}{c}
i_{r}(t) \\
v_{r}(t)-V_{s}
\end{array}\right]=\left[\begin{array}{cc}
\frac{-\sqrt{(1-\alpha)}\left[v_{r}\left(t_{2}\right)-V_{S}\right]}{Z_{r}} & i_{r}\left(t_{2}\right) \\
\frac{i_{r}\left(t_{2}\right) \cdot Z_{r}}{\sqrt{(1-\alpha)}} & v_{r}\left(t_{2}\right)-V_{S}
\end{array}\right]} \\
\times\left[\begin{array}{l}
\sin \left(\omega_{r} \sqrt{(1-\alpha)}\left(t-t_{2}\right)\right) \\
\cos \left(\omega_{r} \sqrt{(1-\alpha)}\left(t-t_{2}\right)\right)
\end{array}\right] \\
t_{3}-t_{2}=\frac{1}{\omega_{r} \sqrt{(1-\alpha)}} \tan ^{-1}\left(\frac{Z_{r}}{\sqrt{(1-\alpha)}} \frac{i_{r}\left(t_{2}\right)}{v_{r}\left(t_{2}\right)-V_{S}}\right)
\end{gathered}
$$

Mode III $\left(t_{3}-t_{4}\right)$ : Since $\mathrm{i}_{\mathrm{r}}$ has reached zero at the end of previous interval, by setting the gate of $\mathrm{Q}_{2}$ at $\mathrm{t}_{3}$, this switch is turned $\mathrm{ON}$ at $\mathrm{ZCS}$. At the end of this mode the resonant voltage $\mathrm{v}_{\mathrm{r}}$ reaches $-\mathrm{V}_{\mathrm{O}}$.

$$
\begin{array}{r}
v_{r}(t)=v_{r}\left(t_{3}\right) \cos \left(\omega_{r} \sqrt{(1-\alpha)}\left(t-t_{3}\right)\right) \\
i_{r}(t)=\frac{-\sqrt{(1-\alpha)} v_{r}\left(t_{3}\right)}{Z_{r}} \sin \left(\omega_{r} \sqrt{(1-\alpha)}\left(t-t_{3}\right)\right) \\
t_{4}-t_{3}=\frac{1}{\omega_{r} \sqrt{(1-\alpha)}} \cos ^{-1} \frac{-V_{o}}{v_{r}\left(t_{3}\right)} \\
=\frac{1}{\omega_{r} \sqrt{(1-\alpha)}}\left[\pi-\cos ^{-1} \frac{V_{o}}{v_{r}\left(t_{3}\right)}\right]
\end{array}
$$

Mode IV $\left(t_{4}-t_{5}\right)$ : The diode $\mathrm{D}$ turns on and the energy stored in $\mathrm{L}_{2}$ starts delivering to the output via $\mathrm{L}_{1}$. At $\mathrm{t}_{5}$ the magnitude of $\mathrm{L}_{2}$ current becomes equal to that of $\mathrm{L}_{1}$ and thus $\mathrm{Q}_{2}$ is turned off at ZCS.

$$
\begin{gathered}
v_{r}(t)=\left[v_{r}\left(t_{4}\right)+\alpha V_{o}\right] \cos \left(\omega_{r}\left(t-t_{4}\right)\right)-\alpha V_{o} \\
i_{r}(t)=\frac{1-\alpha}{Z_{r}}\left[v_{r}\left(t_{4}\right)+\alpha V_{o}\right] \sin \left(\omega_{r}\left(t-t_{4}\right)\right) \\
+\frac{\omega_{r} \alpha(1-\alpha) V_{o}}{Z_{r}}\left(t-t_{4}\right)+i_{r}\left(t_{4}\right) \\
t_{5}-t_{4}=\sin ^{-1}\left(\frac{-Z_{r} i_{r}\left(t_{4}\right)}{(1-\alpha) V_{O}}\right)
\end{gathered}
$$

Mode $V\left(t_{5}-t_{6}\right)$ : The magnitudes of resonant current and diode current decrease linearly until at $t_{6}$ reach zero. At this time D is turned off at ZCS.

$$
v_{r}(t)=v_{r}\left(t_{5}\right)=c t e
$$




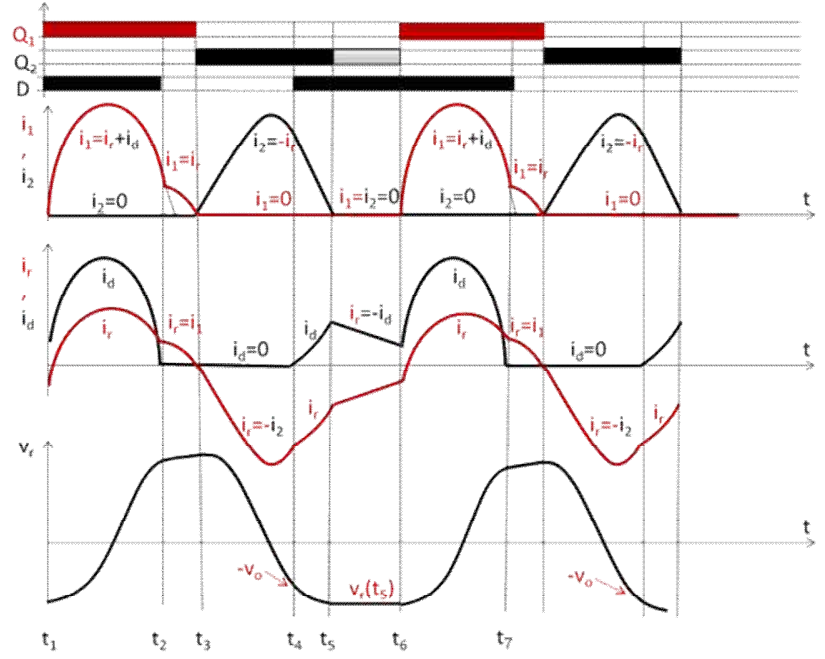

Fig. 3. CCM operation.

$$
\begin{gathered}
i_{r}(t)=\frac{\omega_{r} \alpha(1-\alpha)}{Z_{r}} V_{o}\left(t-t_{5}\right)+i_{r}\left(t_{5}\right) \\
t_{6}-t_{5}=\frac{-Z r_{r}{ }_{r}\left(t_{5}\right)}{\omega_{r} \alpha(1-\alpha) V_{o}}
\end{gathered}
$$

Mode VI $\left(t_{6}-t_{7}\right)$ : The output capacitor C supplies the load. Duration of this interval is determined by the controller so that proper voltage regulation is attained (dead-time control).

\section{B. CCM Operation}

By turning $\mathrm{Q}_{1}$ on prior to $\mathrm{t}_{6}, \mathrm{CCM}$ operation with higher power handling capability than DCM is achieved. The key waveforms are depicted in Fig. 3. Except mode I, all other operating modes are exactly the same as those of DCM. For mode I the equations are as follows.

$$
\begin{array}{r}
v_{r}(t)=\left[v_{r}\left(t_{1}\right)-V_{s}+\alpha V_{o}\right] \\
i_{r}(t)=-\frac{(1-\alpha)}{Z_{r}}\left[v_{r}\left(t_{1}\right)-V_{s}+\alpha V_{o}\right] \sin \left(\omega_{r}\left(t-t_{1}\right)\right) \\
+\frac{\omega_{r} \alpha(1-\alpha) V_{o}}{Z_{r}}\left(t-t_{1}\right)+i_{r}\left(t_{6}\right)
\end{array}
$$

\section{Deep CCM Operation}

By further increasing switching frequency the converter lies in deep-CCM operation as shown in Fig.4. Consider the shaded area in Fig. 4. This Area shows an interval in which $\mathrm{Q}_{1}$ is conducting. At deep-CCM this interval completely lies in the middle of conduction interval of $\mathrm{D}$. Thus, simultaneously energy is drained from the input voltage source and load is fed by the energy stored in the resonant tank. The converter DC voltage gain at deep-CCM is denoted

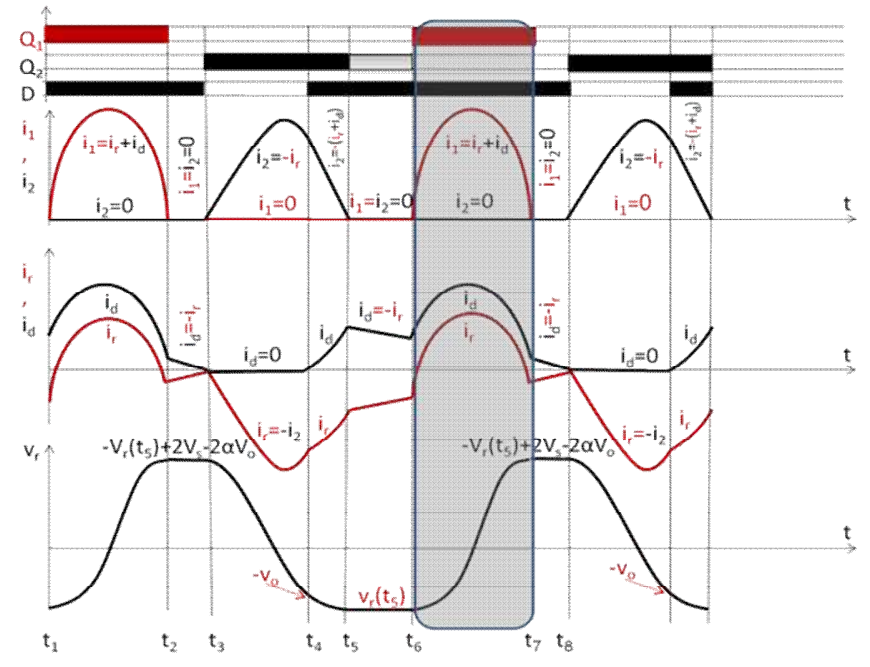

Fig. 4. Operation at deep-CCM.

by $\mathrm{A}_{\mathrm{m}}$.

Mode I $\left(t_{1}-t_{2}\right)$ : At $\mathrm{t}_{1}, \mathrm{Q}_{1}$ turns on at ZCS while the diode D is conducting. The capacitor $\mathrm{C}_{\mathrm{r}}$ is charged through a resonance with $L_{1}$ and $L_{2}$. At the end of this mode the current of $\mathrm{Q}_{1}$ has passed a sinusoidal cycle and again has reached zero. Hence, $\mathrm{Q}_{1}$ is turned off at $\mathrm{t}_{2}$ under the $\mathrm{ZCS}$ conditions.

$$
\begin{gathered}
v_{r}(t)=\left[v_{r}\left(t_{1}\right)-V_{s}+\alpha V_{o}\right] \cos \left(\omega_{r}\left(t-t_{1}\right)\right)+\left[V_{s}-\alpha V_{o}\right](22) \\
i_{r}(t)=-\frac{(1-\alpha)}{Z_{r}}\left[v_{r}\left(t_{1}\right)-V_{s}+\alpha V_{o}\right] \sin \left(\omega_{r}\left(t-t_{1}\right)\right) \\
+\frac{\omega_{r} \alpha(1-\alpha) V_{o}}{Z_{r}}\left(t-t_{1}\right)+i_{r}\left(t_{6}\right) \\
\left(t_{2}-t_{1}\right)=\frac{\pi}{\omega_{r}}
\end{gathered}
$$

Mode II $\left(t_{2}-t_{3}\right)$ : The diode is conducting until at $t_{3}$ its current becomes zero and turns off at ZCS.

$$
\begin{gathered}
v_{r}(t)=v_{r}\left(t_{2}\right)=-v_{r}\left(t_{5}\right)+2 V_{s}-2 \alpha V_{o}=c \\
i_{r}(t)=\frac{\omega_{r} \alpha(1-\alpha)}{Z_{r}} V_{o}\left(t-t_{2}\right)+i_{r}\left(t_{2}\right) \\
t_{3}-t_{2}=\frac{-Z_{r} i_{r}\left(t_{2}\right)}{\omega_{r} \alpha(1-\alpha) V_{O}}
\end{gathered}
$$

Mode III-V $\left(t_{3}-t_{6}\right)$ : All other operating modes are exactly the same as those of DCM. 


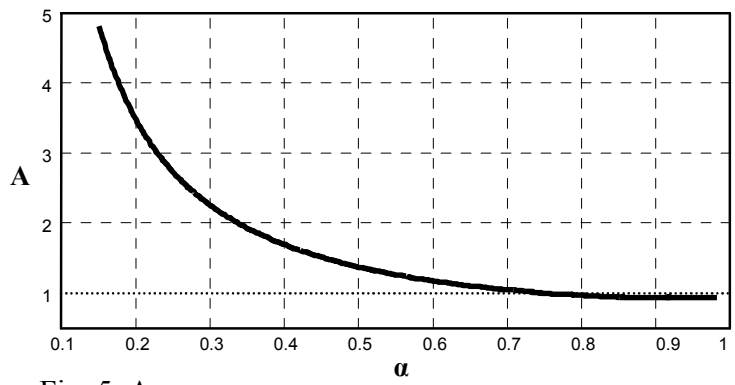

Fig. 5. A versus $\alpha_{\max }$.

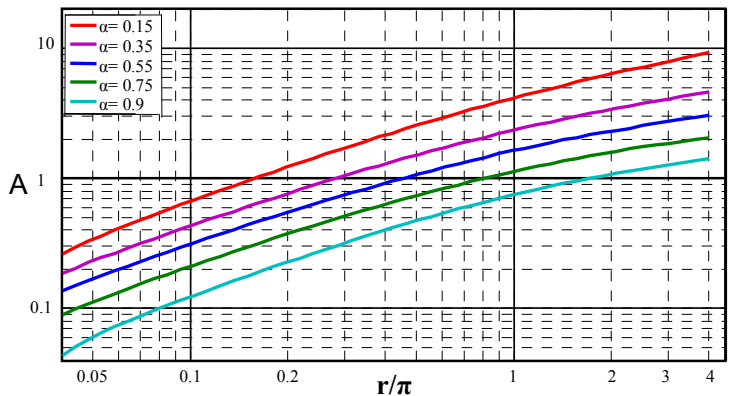

Fig. 6. DC voltage gain at the DCM-CCM boundary vs. $r / \pi$.

\section{DESIGN}

As presented by (28), deep-CCM operation can be attained if the duration of $\mathrm{Q}_{1}$ conduction is less than or equal to the conduction time of diode D. By numerical solving of (28), a maximum value for $\alpha\left(\alpha_{\max }\right)$ is obtained as a function of the converter DC voltage gain. DC voltage gain at $\alpha=\alpha_{\max }$ is sketched in Fig. 5. E.g. for $\mathrm{A}=2, \alpha_{\max }=0.34$ is obtained which means by choosing $\alpha \leq 0.34$ the converter can be set at deep-CCM for $\mathrm{A} \leq 2$.

$$
\left(t_{7}-t_{6}\right) \leq\left(t_{8}-t_{5}\right) \Rightarrow \frac{\pi}{\omega_{r}} \leq\left(t_{8}-t_{5}\right)
$$

By using numerical analysis, DC voltage gain at the boundary of DCM-CCM and deep-CCM are obtained as Figs. 6 and 7. The design is easily accomplished by using Figs. 5-7 based on the requirements.

As an example, consider a $200 \mathrm{~W}$ voltage regulator for $\mathrm{V}_{\mathrm{S}}=200 \mathrm{~V} \pm 10 \%$ to $\mathrm{V}_{\mathrm{O}}=160 \mathrm{~V} \pm 1 \%$ and $\mathrm{f}_{\mathrm{r}}=200 \mathrm{KHz}$.

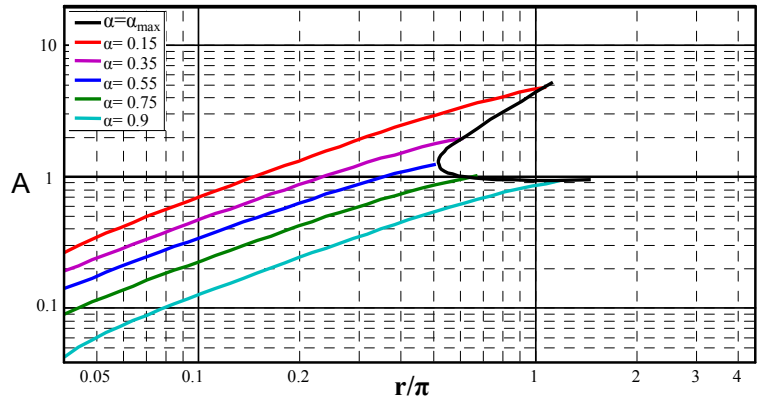

Fig. 7. DC voltage gain at deep-CCM vs. $r / \pi$.

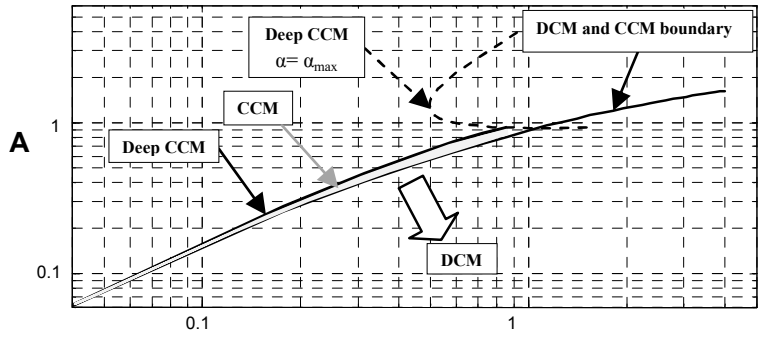

Fig. 8. Converter voltage gain behavior for $\alpha=0.85$.

Step-1) Determining $\alpha$ : By applying $A=A_{\max }=160 / 180$ in Fig. 5, $\alpha_{\max }=1$ is obtained; then $\alpha=0.85$ is selected. Fig. 8 shows the converter behavior and its operating regions Vs. the normalized load $(r / \pi)$. The area between DCM and deep-CCM determines the CCM region.

Step-2) Determining $\mathrm{Z}_{\mathrm{r}}$ : By applying $\mathrm{A}_{\mathrm{m}}=\mathrm{A}_{\max }$ in Fig. 6, $\mathrm{r}=2.41$ is obtained. Then with $20 \%$ overdesign, $Z_{\mathrm{r}}$ is calculated as $\mathrm{Z}_{\mathrm{r}}=160 \mathrm{~V} 2 / 200 \mathrm{~W} / 2.41 / 1.2=44.26 \Omega$.

Step-3) Determining $\mathrm{L}_{1}, \mathrm{~L}_{2}$ : By using $\alpha=0.85$ and $\mathrm{fr}=200 \mathrm{KHz}$ then $\mathrm{L}_{\mathrm{r}}=35.24 \mu \mathrm{H}$ and $\mathrm{C}_{\mathrm{r}}=18 \mathrm{nF}$ are obtained. Then $\mathrm{L}_{1}=41 \mu \mathrm{H}$ and $\mathrm{L}_{2}=235 \mu \mathrm{H}$ are calculated.

Step-4) Determining C: In order to have peak-to-peak output voltage ripple equal to $0.02 \times 160 \mathrm{~V}$ for the worst conditions (almost zero-load), simulation shows that the value of the output capacitor should be $\mathrm{C}=47 \mu \mathrm{F}$.

Soft-switching conditions for all three operating modes are presented in TABLE I.

TABLE I

SOFT-SWITCHING OPERATION

\begin{tabular}{|c|c|c|c|c|c|c|}
\hline & Mode & $\bar{I}$ & II & III & IV & $\overline{\mathrm{V}}$ \\
\hline \multirow{3}{*}{ DCM } & Q1 & on @ ZCS & on & off @ ZCS & off & off \\
\hline & $\overline{\mathrm{Q} 2}$ & $\overline{\text { off }}$ & $\overline{\text { off }}$ & on @ ZCS & on & off @ ZCS \\
\hline & $\bar{D}$ & on & Off @ ZCS & off & on @ ZCS & on \\
\hline \multirow{3}{*}{ CCM } & Q1 & on @ ZCS & on & off @ ZCS & off & off \\
\hline & $\overline{\mathrm{Q} 2}$ & off & off & on@ ZCS & on & off @ ZCS \\
\hline & $\overline{\mathrm{D}}$ & on & off @ ZCS & $\overline{\text { off }}$ & on@ $@ \mathrm{ZCS}$ & on \\
\hline \multirow{3}{*}{$\begin{array}{l}\text { Deep } \\
\text { CСM }\end{array}$} & $\overline{\mathrm{Q} 1}$ & on@ $\mathrm{ZCS}$ & off @ ZCS & off & $\overline{\text { off }}$ & off \\
\hline & $\overline{\mathrm{Q} 2}$ & off & off & on @ $\mathrm{ZCS}$ & on & off @ ZCS \\
\hline & $\bar{D}$ & on & on & off @ ZCS & on @ ZCS & on \\
\hline
\end{tabular}


TABLE II

COMParison OF THE Zeta CONVERTER AND Proposed CONVERTER

\begin{tabular}{|c|c|c|c:c|c|c|c|c|}
\hline Non-Inverting & $\varphi_{1, \max }$ & $\varphi_{2, \max }$ & $\mathrm{C}_{\mathrm{r}}$ & $\mathrm{Q}_{\max }$ & \multicolumn{2}{|c|}{$\begin{array}{c}\text { Current } \\
\text { stress (A) }\end{array}$} & \multicolumn{2}{|c|}{$\begin{array}{c}\text { Voltage } \\
\text { stress }(\mathrm{V})\end{array}$} \\
\cline { 5 - 10 } \\
Buck-Boost & $(\mu \mathrm{Wb})$ & $(\mu \mathrm{Wb})$ & $(\mathrm{nf})$ & $(\mu \mathrm{C})$ & $\mathrm{Q}_{1}$ & $\mathrm{Q}_{2}$ & $\mathrm{Q}_{1}$ & $\mathrm{Q}_{2}$ \\
\hline Proposed & 255 & 761 & 18 & 6.57 & 8 & 4 & 380 & 420 \\
\hline Zeta & 369 & 705 & 800 & 133.6 & 11.8 & N/A & 370 & N/A \\
\hline
\end{tabular}

\section{EVALUATION}

The proposed converter provides soft-switching conditions for both switches at turn-on and turn-off switching instants independent from the load-current and operating voltages. Also, ZCS turn-off condition for the output diode obviates the problem of reverse-recovery. The passive components constitute a high-frequency resonant CLL tank with a relatively small size. Non-inverting step-down/up voltage gain is attainable from DCM to deep-CCM.

In Table II, the designed converter is compared with an ideal PWM Zeta converter. The Zeta converter is chosen since in both converters an inductor exists at the output and the number of passive components is equal. The Zeta converter is designed to have the same operating conditions as $200 \mathrm{~W}, 100 \mathrm{KHz}$, and voltage gain of $160 \mathrm{~V} / 200 \mathrm{~V}$. The switching losses created due the hard-switching operation of Zeta converter are neglected and it is supposed this converter can operate at $100 \mathrm{KHz}$ properly. The inductors of the Zeta converter are also set the same as those of the proposed converter but in order to provide acceptable operating conditions its coupling capacitor is ascertained to have less than $5 \%$ voltage ripple. According to Table II, the sum of current stresses of $\mathrm{Q}_{1}$ and $\mathrm{Q}_{2}$ in the proposed converter are almost equal to the current stress of the switch of Zeta converter. Hence, it can be supposed that the switch current stress of the Zeta converter is shared between the switches of the proposed converter. It implies no additional energy circulation is created in the proposed resonant converter and thus no additional conduction losses are created too.

The maximum magnetic flux $\varphi_{\max }=\mathrm{L} \times \mathrm{I}_{\max }$ and maximum electric charge $\mathrm{Q}_{\max }=\mathrm{C} \times \mathrm{V}_{\max }$ determine the size of inductor and capacitor respectively. According to Table II, the size of inductors in the proposed converter and the ideal Zeta converter are almost the same. However, another advantage of the proposed converter it that the size of its coupling capacitor is 20 times less which is due its resonant operation. The disadvantage of proposed converter is that the voltage stress of $\mathrm{Q}_{2}$ is slightly higher (the additional voltage stresses of the Zeta converter created due to the hard switching operation are neglected).

\section{EXPERIMENTAL RESULTS}

The employed switches are IRF840 (500V, 4A, $\left.\mathrm{R}_{\mathrm{DS}(\mathrm{ON})}=0.85 \Omega\right)$ in series with MUR860 (600V). The rectifying diode is MUR860 in parallel with a $500 \mathrm{pF}$ ceramic capacitor for decreasing its voltage ringing. This small capacitor does not have any considerable effect on the converter operation. The passive elements are $\mathrm{C}_{\mathrm{r}}=18 \mathrm{nf}$ (Metallized Polypropylene (MKP) type), $\mathrm{L}_{1}=41 \mu \mathrm{H}$ (Core: Ferrite 3F3, EI, 13 turns) and $\mathrm{L}_{2}=235 \mu \mathrm{H}$ (Core: Ferrite 3F3, EI, 30 turns).

Soft-switching operation of $\mathrm{Q}_{1}, \mathrm{Q}_{2}$ and diode are presented in Fig. 9. The spiky currents appeared at turn-on instants are due to the output capacitance of the switches. This is a well-known phenomenon of ZCS bridge structures and can be eliminated easily [27]. $\mathrm{Q}_{1}$ is turned off at ZCS and $\mathrm{Q}_{2}$ is turned off at ZVZCS. By resetting the gate signal of $Q_{1}$, its output capacitance is charged through a resonant with $\mathrm{L}_{\mathrm{r}}$ which results in a small reverse current at its turn-off instant. The resonance voltage $\left(v_{r}\right)$ and the ripple of output voltage are presented in Fig. 10. Fig. 11 presents the trajectory of the state variables in state-plane. The closed from of trajectory shows the converter has a stable operation. The converter efficiency and its switching frequency variations vs. output power are illustrated in Fig. 12. According to this figure, by increasing output power the switching frequency is increased to hold the output voltage constant and thus the converter operation state moves from DCM to Deep-CCM. At DCM the converter efficiency is almost constant about $93 \%$ and variations of switching frequency vs. output power are almost linear. At CCM and Deep-CCM increase of efficiency is expected because the peak-to-average of switches current is reduced. This feature is seen at the beginning of the CCM region; however, a small reduction in efficiency is seen around the full-load which is the result of increase of the switches $\mathrm{R}_{\mathrm{DS}(\mathrm{ON})}$ due to increase of the switches junction temperature.

\section{CONCLUSIONS}

A non-inverting resonant buck-boost converter with a few number of element is presented. ZCS conditions are achieved for all semiconductor devices independent from the load-current and operating voltages. Experimental results from a laboratory prototype verified the presented operation and theoretical analysis of the proposed converter. 


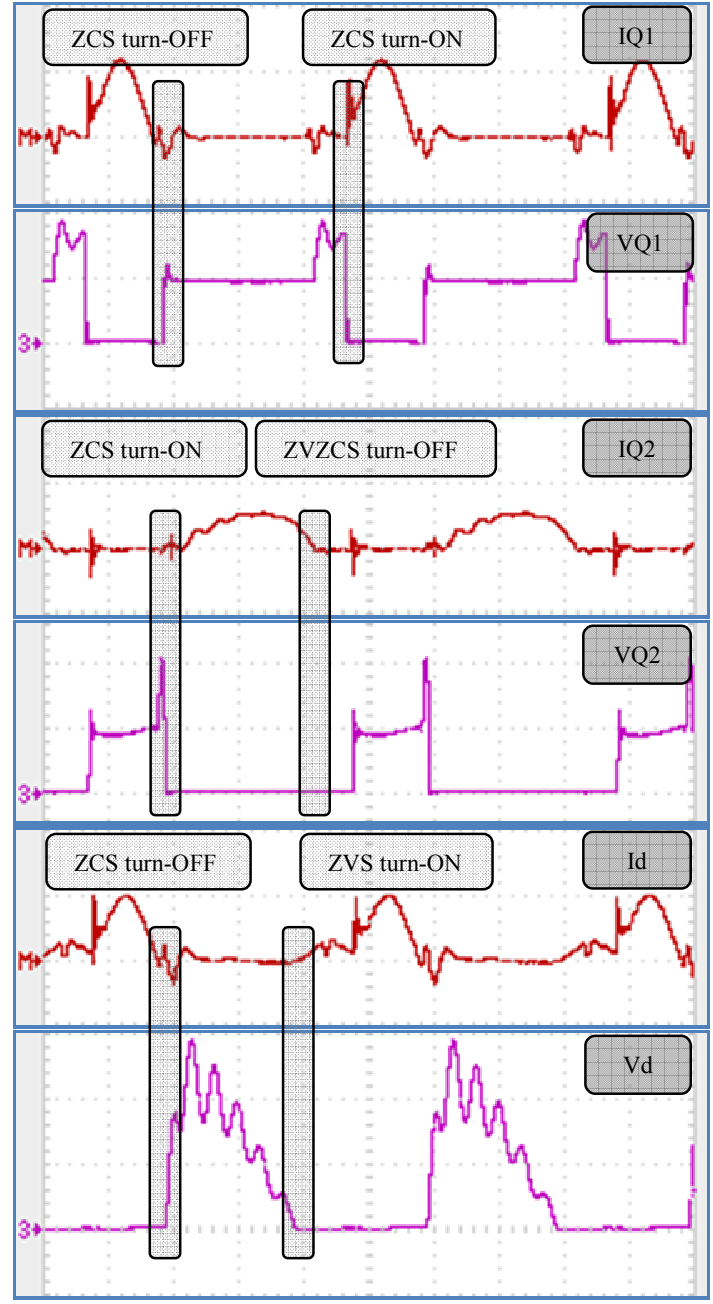

Fig. 9. Soft-switching operation of $\mathrm{Q}_{1}, \mathrm{Q}_{2}, \mathrm{D}$, and resonant voltage $(2.5 \mu \mathrm{s} / \mathrm{div}), 6.67 \mathrm{~A} / \mathrm{div}, 200 \mathrm{~V} / \mathrm{div}$.

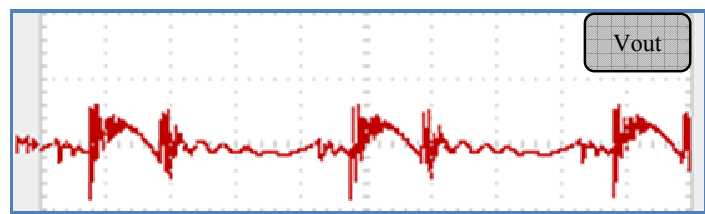

Fig. 10. Ripple output voltage $2 \mathrm{~V} / \mathrm{div}(2.5 \mu \mathrm{s} / \mathrm{div})$.
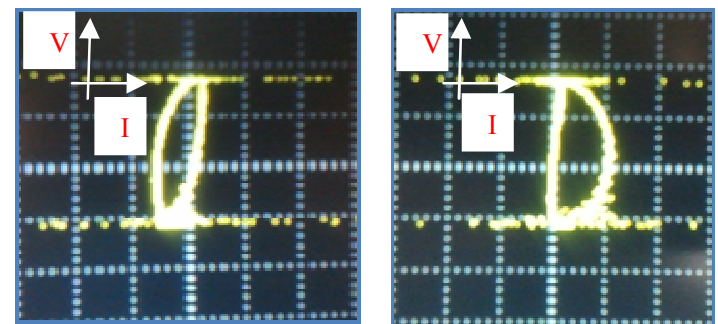

Fig. 11. Trajectories of state variables in the phase plane: $i_{r}$ and $\mathrm{v}_{\mathrm{r}}$ (left), $\mathrm{i}_{\mathrm{d}}$ and $\mathrm{v}_{\mathrm{r}}$ (right), 6.67A/div, $200 \mathrm{~V} /$ div.

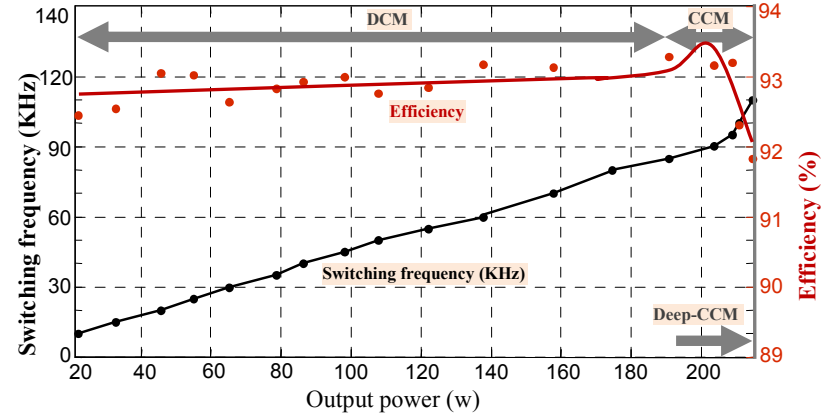

Fig. 12. Switching frequency and efficiency versus output power.

\section{REFERENCES}

[1] B. Sahu and G. A. Rincon-Mora, "A low voltage, dynamic, non-inverting, synchronous buck-boost converter for portable applications," IEEE Trans. Power Electron., Vol. 19, No.2, pp. 443-452, Mar. 2004.

[2] W.-C. Lee, S.-J. Jang, S.-S. Kim, S.-W. Lee, and C.-Y. Won, "A fuel cell generation system with a new active clamp sepic-flyback converter," Journal of Power Electronics, Vol. 9, No. 1, pp. 26-35, Jan. 2009.

[3] C. Jingquan, D. Maksimovic, and R. W. Erickson, "Analysis and design of a low-stress buck-boost converter in universal-input PFC applications," IEEE Trans. Power Electron., Vol. 21, No. 2, pp. 320-329, Mar. 2006.

[4] M. Jabbari and H. Farzanehfard, "New soft switching step-down/up converter with inherent PFC performance," Journal of Power Electronics, Vol. 9, No. 6, pp. 835-844, 2009.

[5] M. Gaboriault and A. Notman, "A high efficiency, non-inverting, buck-boost Dc-Dc converter," Applied Power Electronics Conference and Exposition, pp. 1411-1415, 2004.

[6] R. Paul and D. Maksimovic, "Smooth transition and ripple reduction in 4-switch non-inverting buck-boost power converter for WCDMA RF power amplifier," IEEE ISCAS, pp. 3266-3269, 2008.

[7] C. Restrepo, J. Calvente, A. Cid, A. El Aroudi, and R. Giral, "A non-inverting buck-boost DC-DC switching converter with high efficiency and wide bandwidth," IEEE Trans. Power Electron., Vol. 26, No. 9, pp. 2490 -2503, Sep. 2011.

[8] P.-C. Huang, W.-Q. Wu, H.-H. Ho, and K.-H. Chen, "Hybrid buck-boost feedforward and reduced average inductor current techniques in fast line transient and high-efficiency buck-boost converter," IEEE Trans. Power Electron., Vol. 25, No. 3, pp. 719-730, Mar. 2010.

[9] Y.-J. Lee, A. Khaligh, and A. Emadi, "A compensation technique for smooth transitions in a non-inverting buck-boost converter," IEEE Trans. Power Electron., Vol. 24, No. 4, pp. 1002-1015, Apr. 2009.

[10] Y.-J. Lee, A. Khaligh, A. Chakraborty, and A. Emadi, "Digital combination of buck and boost converters to control a positive buck-boost converter and improve the output transients," IEEE Trans. Power Electron., Vol. 24, No. 5, pp. 1267-1279, May 2009.

[11] N. Mohan, T. M. Undeland, and W. P. Robbins, Power Electronics: Converters, Applications, and Design, 3rd ed. Hoboken, NJ: Wiley, 2002.

[12] B. T. Lin, Y. S. Lee, "A unified approach to modeling, synthesizing, and analyzing quasi-resonant converters," IEEE Trans. Power Electron., Vol. 12, No. 6, pp. 983-992, Nov. 1997. 
[13] D. Maksimovic and S. C'uk, "A general approach to synthesis and analysis of quasi-resonant converters," IEEE Trans. Power Electron., Vol. 6, No. 1, pp. 127-140, Jan. 1991.

[14] K.-H. Liu, R. Oruganti, and F.C. Lee, "Quasi resonant converters-Topologies and characteristics," IEEE Trans. Power Electron., Vol. 2, No. 1, pp. 62-71, 1987.

[15] E. Adib, H. Farzanehfard, "Zero-voltage-transition PWM converters with synchronous rectifier," IEEE Trans. Power Electron., Vol. 25, No. 1, pp. 105-110, Jan. 2010.

[16] E. Adib, H. Farzanehfard, "Family of zero-voltage transition pulse width modulation converters with low auxiliary switch voltage stress," IET Power Electron., Vol. 4, No. 4, pp. 447-453, Apr. 2011.

[17] E. Adib and H. Farzanehfard, "Family of zero current zero voltage transition PWM converters," IET Power Electron., Vol. 1, No. 2, pp. 214-223, Jun. 2008.

[18] M. Jabbari and H. Farzanehfard, "Family of soft switching resonant DC-DC converters," IET Power Electron., Vol. 2, No. 2, pp. 113-124, Mar. 2009.

[19] M. Jabbari, "Unified analysis of switched-resonator converters," IEEE Trans. Power Electron., Vol. 26, No.5, pp. 1364-1376, May 2011.

[20] M. Jabbari and H. Farzanehfard, "New resonant step-down/up converters," IEEE Trans. Power Electron., Vol. 25, No. 1, pp. 249-256, Jan. 2010.

[21] S.-K. Kwon, B. Saha, S.-P. Mun, K. Nishimura, and M. Nakaoka, "Series resonant ZCS-PFM DC-DC converter using high frequency transformer parasitic inductive components and lossless inductive snubber for high power microwave generator," Journal of Power Electronics, Vol. 9, No. 1, pp. 18-25, Jan. 2009.

[22] S.-S. Hong, S.-H. Cho, C.-W. Roh, and S.-K. Han, "Precise analytical solution for the peak gain of llc resonant converters," Journal of Power Electronics, Vol. 10, No. 6, pp. 680-685, Nov. 2010.

[23] H.-S. Choi, "Design consideration of half-bridge llc resonant converter," Journal of Power Electronics, Vol. 7, No. 1, pp. 13-20, Jan. 2007.

[24] F. Dianbo, F. C. Lee, Q. Yang, and F. Wang, "A novel high-power-density three-level LCC resonant converter with constant-power-factor-control for charging applications," IEEE Trans. Power Electron., Vol. 23, No. 5, pp. 2411-2420, Sep. 2008.

[25] D. Fu, Y. Liu, F. C. Lee, and M. Xu, "A novel driving scheme for synchronous rectifiers in LLC resonant converters," IEEE Trans. Power Electron., Vol. 24, No. 5, pp. 1321-1329, May 2009.

[26] M. Jabbari, H. Farzanehfard, and G. Shahgholian, "Isolated Topologies of Switched-Resonator Converters," Journal of Power Electronics, Vol. 10, No. 2, pp. 125-131, Mar. 2010.

[27] G. Ivensky, I. Zeltser, A. Kats, and S. Ben-Yaakov, "Reducing IGBT losses in ZCS series resonant converters," IEEE Trans. Ind. Electron., Vol. 46, No. 1, pp. 67-74, Feb. 1999.

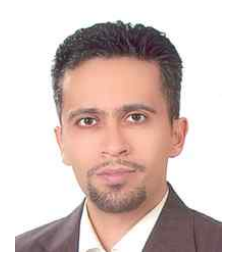

Masoud Jabbari (S'08-M'10) was born in Isfahan, Iran, in 1979. He received the B.S. degree from Kashan University, Kashan, Iran, in 2001, and, the M.S. and Ph.D. degrees from Isfahan University of Technology, Isfahan, Iran, in 2003 and 2009, respectively, all in electrical engineering. His research interests include soft-switching techniques in high-frequency high-power converters, power-factor corrections, and active power filters. Besides, he has vast studies on modern physics, especially on quantum mechanics. One of his researches is the family of switched-resonator converters in power-electronics.

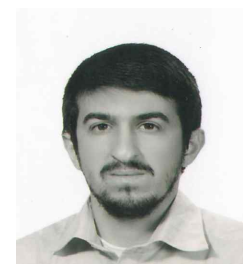

Saead Sharifi was born in Najafabad, Isfahan, Iran, in 1985. He received the B.S. and M.S. degrees in electrical engineering from Islamic Azad University, Isfahan, in 2008 and 2012, respectively. His current research interests include soft switching techniques in $\mathrm{dc}-\mathrm{dc}$ converters.

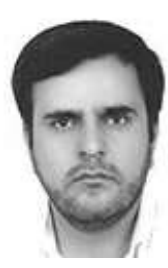

Ghazanfar Shahgholian was born in Isfahan, Iran, on December 7, 1968. He graduated with a degree in Electrical Engineering from the Isfahan University of Technology (IUT), Isfahan, Iran, in 1992. He received his M.Sc and $\mathrm{PhD}$ in Electrical Engineering from Tabriz University, Tabriz, Iran in 1994 and from the Islamic Azad University, Science and Research Branch, Tehran, Iran, in 2006, respectively. He is now an Associate Professor in the Department of Electrical Engineering, Faculty of Engineering, Islamic Azad University, Najaf Abad Branch. His teaching and research interests include the application of control theory to power system dynamics, power electronics and power system simulation. 